ORIGINAL RESEARCH PAPER

\title{
EFFECT OF LACTIC FERMENTATION ON NUTRITIONAL POTENTIAL OF MULTIGRAIN FLOURS BASED ON WHEAT, RYE AND OAT
}

\author{
IULIANA APRODU, CARMEN BOLEA, IULIANA BANU*
}

Dunarea de Jos University of Galati, Faculty of Food Science and Engineering, Domnească Street 111, 800201, Galati, Romania

*Corresponding author: iuliana.banu@ugal.ro

Received on 10 January 2019

Revised on 18 February 2019

\begin{abstract}
This study was focused on the multigrain flours obtained by milling blends with various amounts of wheat, rye and hulled oat, and on the sourdoughs prepared out of these flours using different commercial starter culture. The folate and total phenol levels and 2,2-diphenyl-1-picrylhydrazyl radical scavenging activity (DPPH-RSA) of multigrain flours increased with the addition level of rye and hulled oat. Among the fractions obtained through milling, higher levels of folates were registered in brans, followed by shorts and then by flours. The folate contents in brans and shorts were about of 1-1.4 times higher than in the flours. The sourdough fermentation realized with different commercial starter cultures induced the increase of the total phenols content and DPPH-RSA. The highest levels of folates were obtained when fermenting the flour suspensions with Lactobacillus delbrueckii subsp. Bulgaricus and Streptococcus thermophilus, followed by samples with Lactococcus lactis subsp. Lactis and Leuconostoc. The sourdough fermented with Lactobacillus rhamnosus, Lactobacillus brevis and Lactobacillus plantarum had lower folate contents compared to the corresponding controls obtained through spontaneous fermentation. The obtained results suggest that both the type of cereals used to obtain the flours and the starter culture used to prepare the sourdoughs are suitable tools which worth be used for modulating the nutritional profile of the baking products.
\end{abstract}

Keywords: multigrain milling fractions, total phenol content, antioxidant activity, folates, sourdough

\section{Introduction}

Cereals are important sources of phytochemicals, including folates and phenolic acids. The content of such phytochemicals varies with the type of cereal. Different studies available in the literature indicate that the folate content in cereals decrease in following order: barley $(717.5 \mathrm{ng} / \mathrm{g})>$ rye $(693 \mathrm{ng} / \mathrm{g})>$ oat $(565.8 \mathrm{ng} / \mathrm{g})>$ wheat

https//doi.org/10.35219/foodtechnology.2019.1.05 
$(561 \mathrm{ng} / \mathrm{g})$, while the mean of total phenolic content decrease in following order: rye $(693 \mu \mathrm{g} / \mathrm{g})>$ wheat $(664 \mu \mathrm{g} / \mathrm{g})>$ oat $(531 \mu \mathrm{g} / \mathrm{g})>$ barley $(463.12 \mu \mathrm{g} / \mathrm{g})$ (Andersson et al., 2008; Nystrom et al., 2008; Li et al., 2008; Shewry et al., 2008).

The reason for cereals milling is to separate the starchy endosperm by the aleurone, pericarp layers and germ, followed by endosperm grinding into flour. Taking into account that the most important nutritional components are located in the aleurone layer, through the milling process these components are mainly directed towards the bran. Anyway, depending on the extraction rate of the flours, different proportions of aleurone layers might participate to the formation of flours. Therefore, the extraction rate has a high influence on the nutritional value of flours. According to Dewettinck et al. (2008), the content of phytochemicals, minerals and total fiber rate are directly related to the flours extraction. Therefore, the nutritional components of flours can be modulated by choosing a certain extraction rate, in such way to get technological properties of flours suitable for the type of bakery products that are to be obtained. The improvement of the nutritional potential of flours can be achieved by blending different types of flours, usually the wheat flour with various percentages of flours from other cereals, pseudo-cereals or vegetables, to obtain the composite flours. A less studied alternative, recently presented by Tulse et al. (2014), consists in blending the cereals followed by their milling to obtain multigrain flours.

Regardless of the procedure used to obtain the flours, the use of sourdough fermentation stage during the breadmaking process is a good opportunity to improve the bakery products quality, including the phytochemicals bioavailability (Poutanen et al., 2009).

The objective of this study was to investigate the effect of sourdough fermentation on the folate and phenolic acid contents and on antioxidant activity of multigrain flours. Different commercial starter cultures consisting of lactic acid bacteria (LAB) and multigrain flours based on wheat with different addition levels of rye and hulled oat were used to prepare the sourdoughs.

\section{Materials and Methods}

\section{Materials}

Wheat (Boema variety; $13.4 \%$ protein, $2.1 \%$ fat, $1.65 \%$ ash), rye (Suceveana variety; $9.8 \%$ protein, $1.8 \%$ fat, $1.75 \%$ ash) grown in South East Romanian Plain, harvested in 2016 , and hulled oat (13.8\% protein, $5.2 \%$ fat, $1.92 \%$ ash) purchased from Galati (Romania) market were used in the experiments.

Three different commercial strains were used for preparing the sourdoughs out of the multigrain flours: starter culture 1 (SC1) - DI-PROX MTTX1 from EDR Ingredients (Romania) consisting of a mixture of Lactobacillus rhamnosus, Lactobacillus brevis and Lactobacillus plantarum; starter culture 2 (SC2) - YF-811 from Chr. Hansen (Romania) consisting of Lactobacillus delbrueckii subsp. Bulgaricus and Streptococcus thermophilus; starter culture 3 (SC3) - CHN-22 from Chr. Hansen (Romania) consisting of Lactococcus lactis subsp. Lactis and 
Leuconostoc. The inoculum size used for preparing the sourdoughs was according to producer recommendations.

\section{Multigrain flours preparation}

Wheat $(\mathrm{W})$, rye $(\mathrm{R})$ and hulled oat $(\mathrm{O})$ were blended in the following ratios: $80: 10: 10 \quad(80 \mathrm{~W}+10 \mathrm{R}+10 \mathrm{O}), \quad 70: 15: 15 \quad(70 \mathrm{~W}+15 \mathrm{R}+15 \mathrm{O}) \quad$ and $60: 20: 20$ $(60 \mathrm{~W}+20 \mathrm{R}+20 \mathrm{O})$, followed the milling using the Buhler laboratory mill MLU (Buhler, Uzwil, Switzerland), according to the procedure described by Aprodu and Banu (2017), and Aprodu et al. (2017). For each cereal mixture three milling products were collected as follows: one multigrain flour (F10, F15 and F20 obtained from cereal blends including 10,15 and 20\% rye and hulled oat, respectively), one bran stream (B10, B15 and B20 obtained from cereal blends including 10, 15 and $20 \%$ rye and hulled oat, respectively) and one short stream (S10, S15 and S20 obtained from cereal blends including 10, 15 and 20\% rye and hulled oat, respectively). The multigrain flours formed through milling the three multigrain blends, $\quad 80 \mathrm{~W}+10 \mathrm{R}+10 \mathrm{O} \quad(\mathrm{F} 10), \quad 70 \mathrm{~W}+15 \mathrm{R}+15 \mathrm{O} \quad(\mathrm{F} 15)$ and $60 \mathrm{~W}+20 \mathrm{R}+20 \mathrm{O}(\mathrm{F} 20)$, had extraction rates decreasing with the increase of the wheat substitution level as follows: $72.2 \%, 69 \%$ and $66.2 \%$, respectively.

\section{Sourdough preparation}

In order to obtain the sourdoughs, the multigrain flours were first mixed with tap water (ratio 1:2) to obtain a dough yield of 300. After inoculating the multigrain flour suspensions with starter culture, fermentation was carried out for 20 hours at $30^{\circ} \mathrm{C}$. For all tested multigrain flours, control samples (C10, C15 and $\mathrm{C} 20$ obtained with multigrain flours having 10,15 and $20 \%$ of rye and hulled oat) were prepared without starter cultures addition, by spontaneous fermentation under the condition specified for the sourdough samples. Samples codification is provided in Table 1.

Table 1. Codification of the controls and sourdough samples used in the experiment

\begin{tabular}{lcccc}
\hline $\begin{array}{l}\text { Multigrain } \\
\text { flour }\end{array}$ & Without & $\mathrm{SC} 1$ & $\mathrm{SC} 2$ & $\mathrm{SC} 3$ \\
\hline F10 & $\mathrm{C} 10$ & $\mathrm{SC} 1 \_10$ & $\mathrm{SC} 2 \_10$ & $\mathrm{SC} 3 \_10$ \\
F15 & $\mathrm{C} 15$ & $\mathrm{SC} 1 \_15$ & $\mathrm{SC} 2 \_15$ & $\mathrm{SC} 3$ 15 \\
F20 & $\mathrm{C} 20$ & $\mathrm{SC1} 20$ & $\mathrm{SC2} 20$ & $\mathrm{SC} 320$ \\
\hline
\end{tabular}

\section{Multigrain flours and sourdough characterization}

The total phenolic content (TPC) was quantified using the Folin Ciocalteu method described by Singleton and Rossi (1965) and modified by Gao et al. (2002) and was expressed as $\mathrm{mg}$ ferulic acid equivalent (FAE) per $\mathrm{g}$ d.w.

The antioxidant activity was quantified as the 2,2-diphenyl-1-picrylhydrazyl radical scavenging activity (DPPH RSA), using the method described by BrandWilliams et al. (1995) and modified by Beta et al. (2005).

The $\mathrm{pH}$ of the sourdoughs was measurement according to SR ISO 90/2007 (ASRO 2008), using a Hanna digital pH-meter. 
The content of lactic and acetic acids of sourdough samples were determined using dedicated R-Biopharm kits (Boehringer Mannheim). Producer recommendation was strictly followed for lactic and acetic acids quantification.

The content of folic acid was determined using the competitive enzyme immunoassay Ridascreen ${ }^{\circledR F}$ Fast Folic Acid (RBiopharm Rhone Ltd.) specially designed for the quantification of folic acid in foods. The procedure indicated by the manufacturer was followed. The optical density of the microtiter plate was measured using a plate reader (Stat Fax ${ }^{\circledR} 4700$, Awarness Technology, Inc.) and the software RIDA ${ }^{\circledR}$ Soft Win (R-Biopharm AG, Germany) was used for folic acid content quantification.

\section{Statistical analysis}

The experiments were carried out in triplicate. Significant differences among results were determined through analysis of variance, performed with Microsoft Excel software.

\section{Results and discussion}

\section{Characterization of the multigrain milling fractions}

The fractions obtained through milling the multigrain mixtures with different percentages of wheat, rye and hulled oat were characterized in terms of antioxidant activity, TPC and folate content. In Figure 1 are presented the TPC and DPPHRSA results on multigrain flours, brans and shorts.

The levels of TPC varied from 240.57 to $321.17 \mathrm{mg} \mathrm{FAE} / \mathrm{g}$ d.w. in flours with increasing contents of rye and hulled oat in the blends. The highest TPC values were found in shorts arising from the cereal blends with 10 and $15 \%$ rye and hulled oat (Figure 1a). In case of the blends with $20 \%$ rye and hulled oat, the highest amount of phenolic compounds was directed toward bran, suggesting that during milling a part of the aleurone layer, especial from hulled oat kernels, remained attached to the outer layers. This observation is in agreement with Aprodu and Banu (2017) who noted that the bran stream resulting from oat milling has flattened and large particles with large amounts of adherent endosperm.

The trend registered for DPPH-RSA was similar to the TPC; higher DPPH-RSA values were found for brans and shorts compared to the flours. Anyway, unlike the TPC values, the antioxidant activity of the flours is closer of those of the corresponding brans (Figure 1). In addition, one can note that, for all studied multigrain blends subjected to milling, the DPPH-RSA values were higher for shorts than for corresponding bran fractions. These results might be due to the presence of the hulled oat within blends. According to Hitayezu et al. (2015) the polyphenolic compounds from oat are phenolic acids, flavonoids and avenanthramides, and Emmons et al. (1999) reported that the main avenanthramides present a strong scavenging activity. Hitayezu et al. (2015) found a significant correlation between avenanthramides and radical scavenging activity, but not between avenanthramides and phenolic acids, suggesting the great importance of the contribution of avenanthramides to the antioxidant activity. 

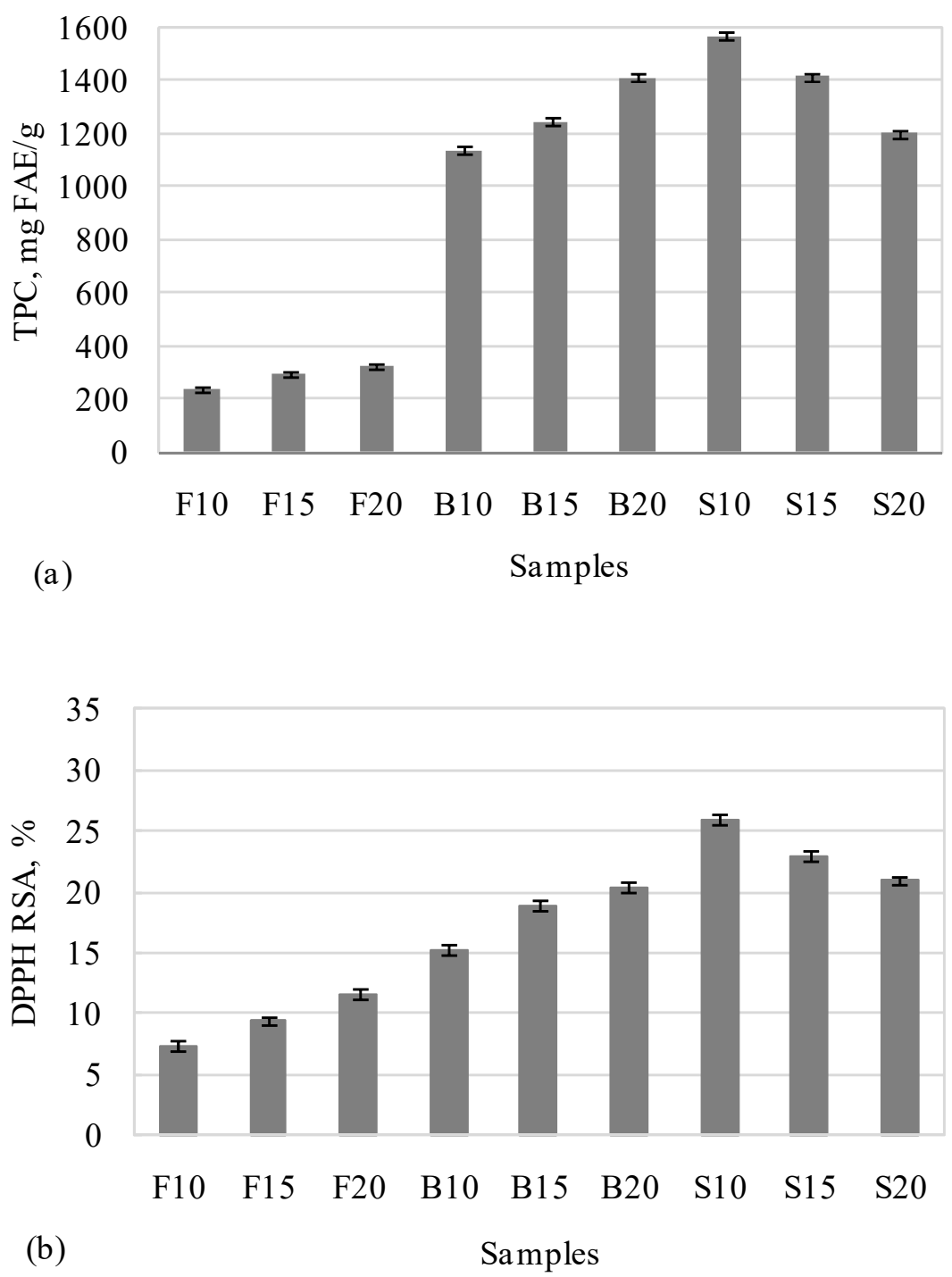

Figure 1. Total phenol content (a) and DPPH-RSA (b) of multigrain milling fractions

Regarding the folate contents in the multigrain milling fractions, our results indicated the increase of the folates amount present in the flours and shorts with increasing the wheat substitution level by rye and hulled oat within blends (Figure 2). These observations are in agreement with Nystrom et al. (2008), Li et al. (2008) and Shewry et al. (2008), who reported that rye has higher folates content than oats and even higher that wheat.

Our results indicated the highest folate levels in shorts, followed by brans and then by flours. In case of wheat, Arcot et al. (2002) reported that the highest content of 
folates is located in the aleurone layer, and there is a significant correlation between ash and folate contents. On the other hand, when studying the oat grains, Edelmann et al. (2012) showed that the content of folates in the endosperm is about 0.7-0.8 times lower compared to the whole oat, while in bran there is about 1.3-1.5 times higher than in the whole oat. Moreover, they reported no significant correlation between ash and folates contents in oat milling fractions. Our results indicated that in case of milling multigrain blends including wheat, rye and hulled oat, the content of folates in the bran and short fractions is about 1.3-1.4 and 1-1.3 times higher, respectively compared to the corresponding flours.

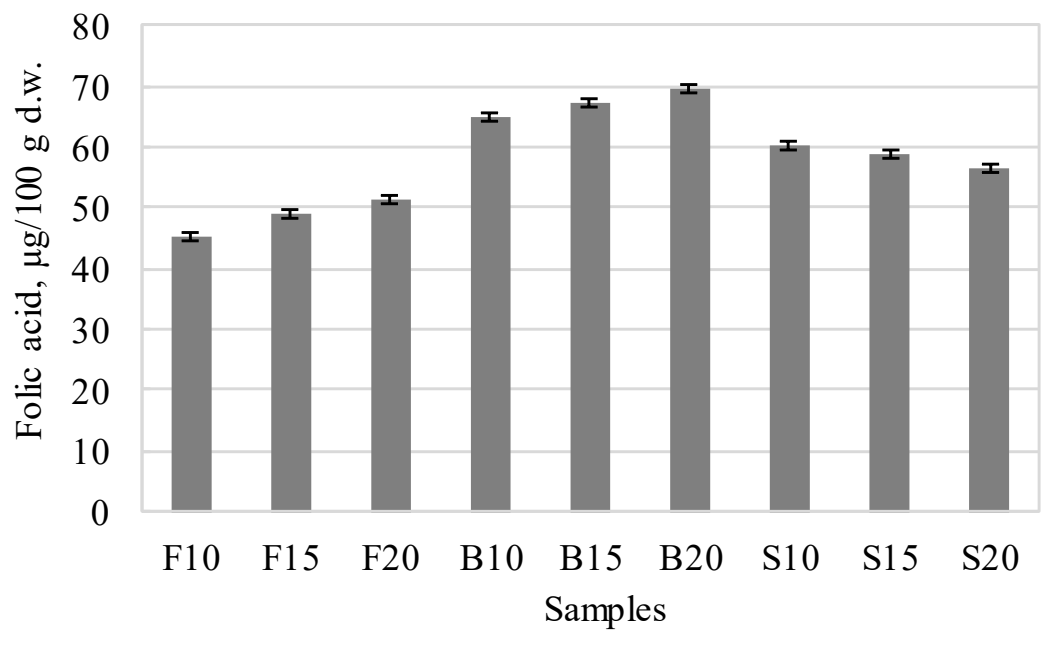

Figure 2. Folates contents of multigrain milling fractions

\section{Characterization of the sourdough}

The multigrain flours were used to obtain sourdoughs through fermentation for $20 \mathrm{~h}$ at $30^{\circ} \mathrm{C}$. At the end of this period, the intensity of lactic acid bacteria metabolic activity was estimated by quantifying the main fermentation metabolites.

The lactic acid and acetic acid contents of sourdoughs increased with the wheat substitution level by rye and hulled oat in the blends, both in control samples (C) and samples fermented with culture starter (SC1, SC2 and SC3) (Figure 3a).

The highest amounts of lactic acid were found in the sourdoughs prepared with SC3 followed by the ones prepared with SC2, while the lower values were registered for control samples. Regarding the acetic acid, higher contents were obtained in case of control samples, followed the sourdough prepared with $\mathrm{SC}$, while the lowest value was obtained for sourdough prepared with SC2 (Figure 3a). Moreover, the sourdough prepared with $\mathrm{SC} 2$ had the lowest $\mathrm{pH}$ and the highest lactic acid/acetic acid ratio (Figure 3b). In case of all controls and sourdough samples prepared with $\mathrm{SC} 1$ and $\mathrm{SC} 3$, the lactic acid/acetic acid ratio increased with the levels of rye and hulled oat within cereal blends, while in case of sourdough 
prepared with SC2 the lactic acid/acetic acid ratio decreased with increasing the wheat substitution level.
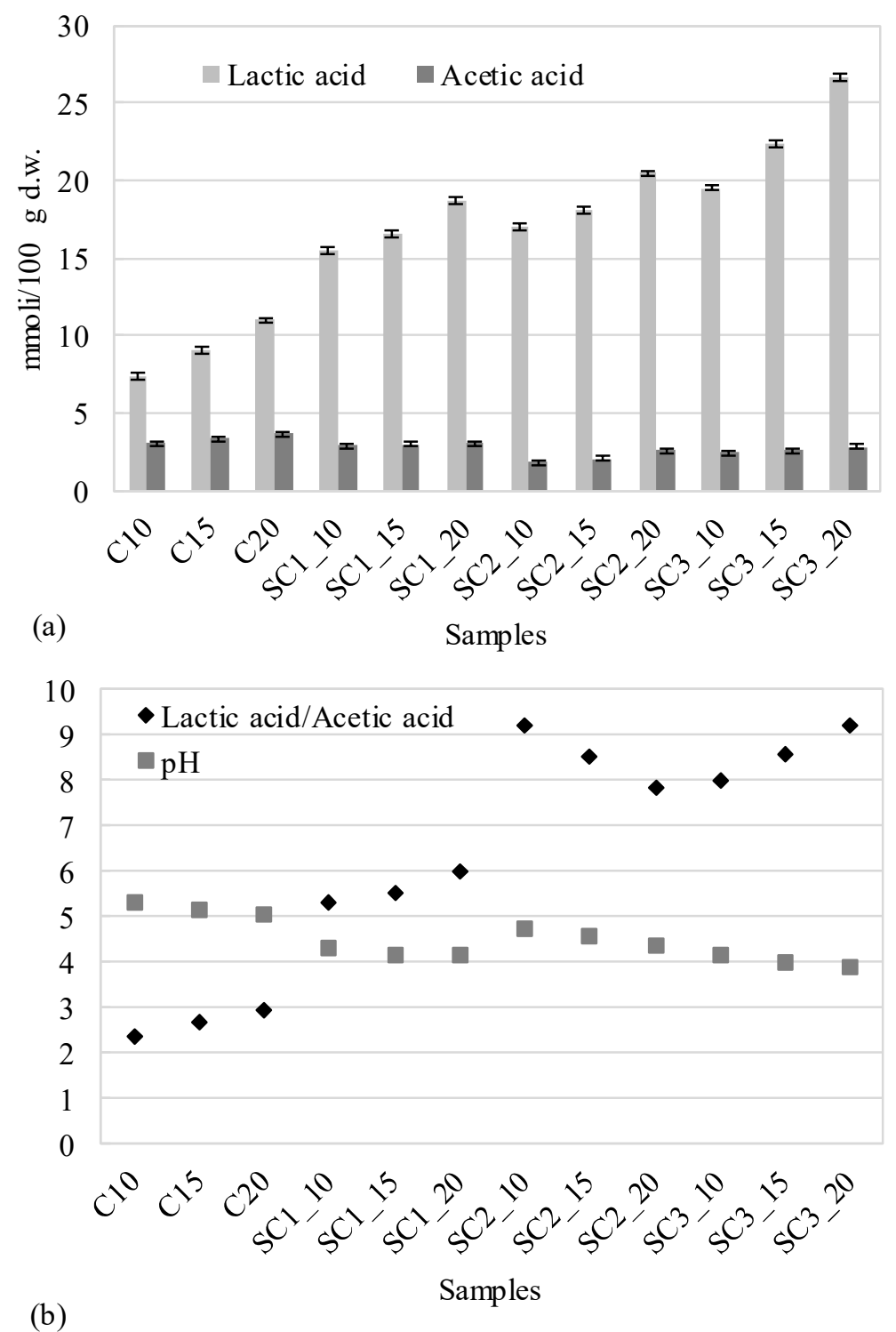

Figure 3. The production of lactic acid and acetic acid (a), lactic acid/acetic acid and $\mathrm{pH}$ (b) of during sourdoughs prepared without starter culture (C) and sourdoughs fermented with starter culture (SC)

The higher lactic acid/acetic acid ratio obtained in case of sourdough samples prepared with SC2 and SC3 might be explained by the fact that these starter cultures include homofermentative LAB, such as Streptococcus thermophiles and Lactococcus lactis, respectively. When compared to the corresponding multigrain 
flours, the sourdough fermentation resulted in the increase of TPC and DPPH-RSA (Figure 1 and Figure 4). According to Dordevic et al. (2010) and Banu et al. (2010, 2011) the fermentation create condition for the increase of enzymatic activity of the endogenous enzyme, that act on cereal cell walls, causing the release and/or synthesis of some bioactive compounds.
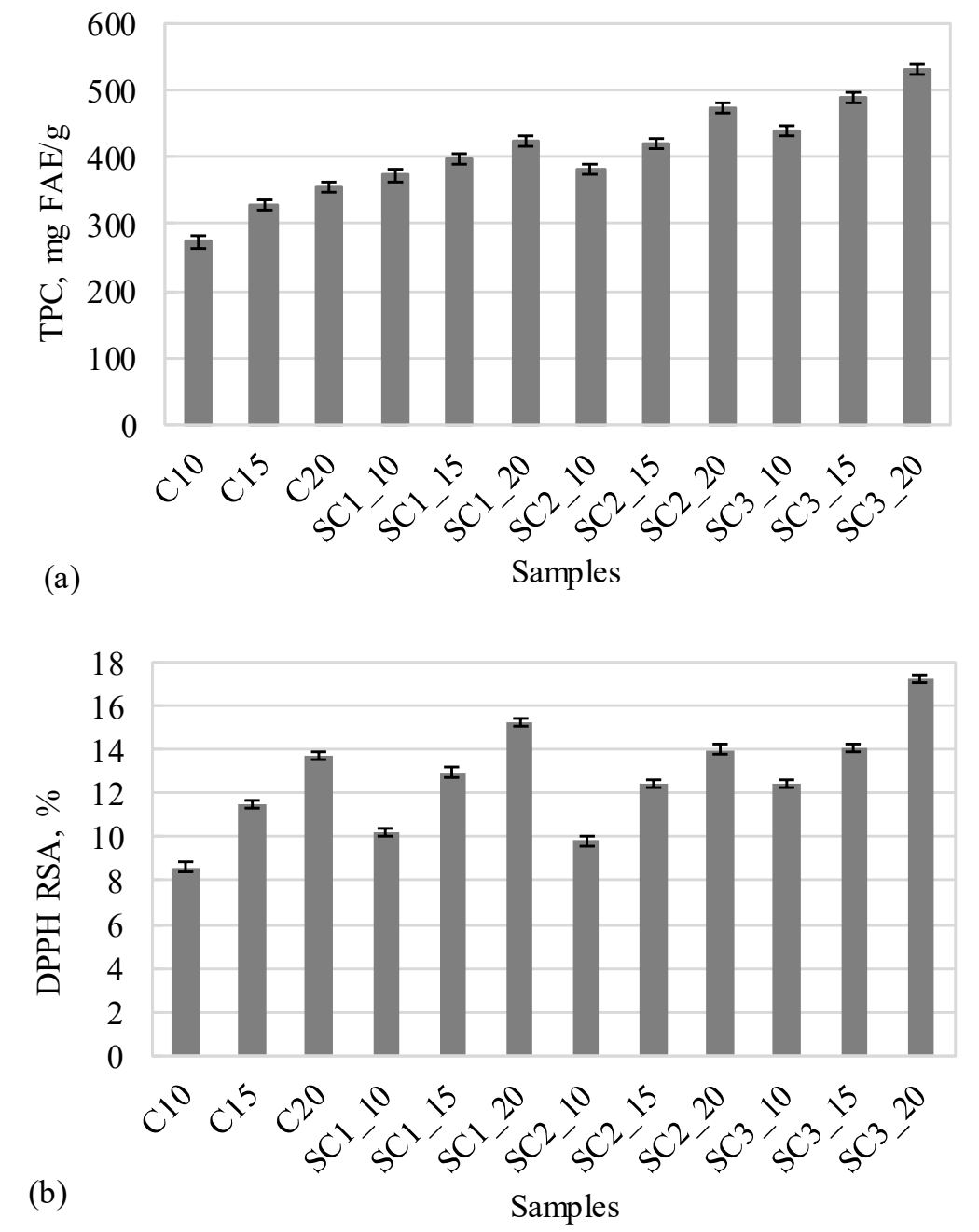

Figure 4. The total phenolic contents (a) and antioxidant activity (b) of the sourdoughs prepared without starter culture (C) and sourdoughs fermented with starter culture (SC)

Taking into account that the optimum $\mathrm{pH}$ values of enzymes acting on cell walls are different, Dordevic et al. (2010) consider that the type of fermentation and the $\mathrm{LAB}$ species influence the accumulation of bioactive compounds in sourdough. Our results indicated higher TPC and DPPH-RSA values for sourdough fermented with $\mathrm{SC} 1$ and $\mathrm{SC}$. These sourdough samples had the lower $\mathrm{pH}$ values after 
fermentation (Figure 3), most probably causing the increase of the levels of easily extractible phenolic compounds (Banu et al., 2010).

The ability of LAB to produce folates varies from one strain to another. Different strains of Lactobacillus acidophilus, Lactobacillus bulgaricus, Lactobacillus plantarum, Lactobacillus fermentum, Streptococcus thermophilus and Lactococcus lactis have the ability to produce folates, but some of them might equally consume the folate (Capozzi et al., 2012). According to Kariluoto et al. (2004), during sourdough fermentation higher amounts of folates can be produced than required to be consumed by the LAB. Our results indicated that higher levels of folates were obtained when fermenting the multigrain flour suspensions with $\mathrm{SC} 2$, followed by sourdough samples prepared with SC3 and SC1 (Figure 5).

In fact, when comparing the folates levels of sourdoughs fermented with LAB and sourdoughs obtained through spontaneous fermentation (controls), one can see that the sourdough prepared with SC1 had lower folate amounts in respect to the corresponding control samples (Figure 5). Most probably, the strains from SC1 consume more folates than can produce during sourdough fermentation. Moreover, the intracellular accumulation of the synthetized folate should be considered (Hugenholtz et al., 2002). For instance, Sybesma et al. (2003) reported that $L$. lactis strain MG1363 is able to intracellularly accumulate $90 \%$ of the folate, releasing only small amounts into the fermentation medium.

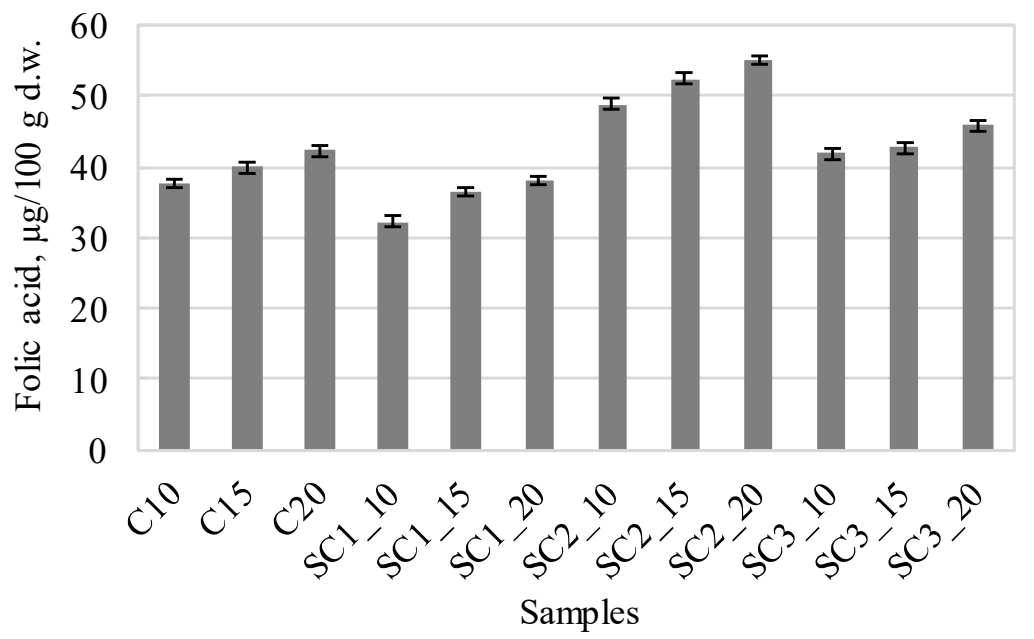

Figure 5. Folic acid content of the sourdoughs prepared without starter culture (C) and sourdoughs fermented with starter culture (SC)

\section{Conclusions}

The amounts of folate, phenolic acid and antioxidant activity of the multigrain flours, brans and short increased with the levels of rye and hulled oat in the 
multigrain blends. The same trend was registered for TPC and DPPH-RSA in the case of multigrain flour, bran and short fractions. Shorts resulted through milling the multigrain blends with 10 and $15 \%$ rye and hulled oat had the highest contents of TPC among the obtained mill streams, while in case of multigrain blends with $20 \%$ rye and hulled oat, the highest TPC value was registered in bran. Regardless of the investigated multigrain blend, higher DPPH-RSA values were found for shorts than from brans. Finally, higher levels of folates were registered in brans and shorts, the amounts being about 1.3-1.4 and 1-1.3 times higher compared to the flours.

The sourdough fermentation induced the increase of TPC and DPPH-RSA compared to the flours. The LAB species from starter cultures impacted the accumulation of bioactive compounds in sourdoughs. The LAB metabolic end products accumulated in the sourdough increased the levels of easily extractible bioactive compounds. The accumulation of folates in the sourdough samples varied with the bacterial strains from the starter culture, suggesting that the LAB alike consume and produce folates.

\section{Acknowledgments}

This work was supported by a grant of the Romanian National Authority for Scientific Research and Innovation, CNCS/CCCDI - UEFISCDI, project number PN-III-P2-2.1-BG-2016-0143, within PNCDI III.

\section{References}

Andersson, A., Lampi, A.M, Nystrom,L., Piironen, V., Li, L., Ward, J.L., Gebruers, K., Courtin, C.M., Delcour, J., Bros,D., Fras, A., Dynkowska, W., Rakszegi, M., Bedo,Z., Shewry, P., Aman, P. 2008. Phytochemical and dietary fiber components in barley varieties in the HEALTHGRAIN diversity screen. Journal of Agriculture and Food Chemistry, 56, 9767-9776.

Aprodu, I., Banu, I. 2017. Milling, functional and thermo-mechanical properties of wheat, rye, triticale, barley and oat. Journal of Cereal Science, 77, 42-48.

Aprodu, I., Horincar, G., Banu, I. 2017. Functional performance of various flours obtained through multigrain milling, 31st EFFoST International Conference, Food Science and Technology Challenges for the 21st Century - Research to Progress Society, 13-16 Noiembrie 2017, Sitges, Spania.

Arcot, J., Wootton, M., Alury H.Y. Chan, S., Ashok, S. 2002. Folate levels in twelve Australian wheats and changes during processing into bread. Food Australia, 54, 18-20.

ASRO 2008. Metode de analiză a cerealelor și produselor de măciniș. SR 90:2007, București.

Banu, I., Vasilean, I., Aprodu, I. 2010. Effect of lactic fermentation on antioxidant capacity of rye sourdough and bread. Food Science and Technology Research, 16, 571-576.

Banu, I., Vasilean, I., Aprodu, I. 2011. Effect of selected parameters of the sourdough rye fermentation on the activity of some mixed starter culture. Food Biotechnology, 25, 275-291. 
Beta, T., Nam, S., Dexter, J. Sapirstein, H. 2005. Phenolic content and antioxidant activity of pearled wheat and roller milled fractions. Cereal Chemistry, 82, 390-393.

Brand-Williams, W., Cuvelier, M.E., Berset, C. 1995. Use of a free radical method to evaluate antioxidant activity. Lebensmittel Wissenschaft und Technologie, 28, 25-30.

Capozzi, V., Russo, P., Duenas, M.T., Lopez, P., Spano, G. 2012. Lactic acid bacteria producing B-group vitamins: a great potential for functional cereals products. Applied Microbiology and Biotechnology, 96, 1383-1394.

Dewettinck, K., van Bockstaele, F., Kuhne, B., van de Walle, D., Courtens, T.M. Gellynck, X. 2008. Nutritional value of bread: influence of processing, food interaction and consumer perception. Journal of Cereal Science, 48, 243-257.

Dordevic, T.H., Siler-Marinkovic, S.S., Dimitrijevic-Brankovic, S.I. 2010. Effect of fermentation on antioxidant properties of some cereals and pseudo cereals. Food Chemistry, 119, 957-963.

Edelmann, M., Kariluoto, S., Nystrom, L., Piironen, V. 2012. Folate in oats and its milling fractions. Food Chemistry, 135, 1938-1947.

Emmons, C.L., Peterson, D.M., Paul, G.L. 1999. Antioxidant capacity of oat (Avena sativa L.) extracts. 2. In vitro antioxidant activity and contents of phenolic and tocol antioxidants. Journal of the Agriculture and Food Chemistry, 47, 4894-4898.

Gao, L., Wang, S., Oomah, B.D., Mazza, G. 2002. Wheat quality: antioxidant activity of wheat millstreams. In: Ng, P.,Wrigley, C.W. (Eds.), Wheat Quality Elucidation. AACC International, St. Paul, MN, pp. 219-233.

Hitayezu, R., Baakdah, M.M., Kinnin, J., Henderson, K., Tsopmo, A. 2015. Antioxidant activity, avenanthramide and phenolic acid contents of oat milling fractions. Journal of Cereal Science, 63, 35-40.

Hugenholtz, J. Sybesma, W., Groot, M. N., Wisselink, W., Ladero, V., Burgess, K., Savoy, G. 2002. Metabolic engineering of lactic acid bacteria for the production of nutraceuticals. In: Siezen R.J., Kok J., Abee T., Schasfsma G. (eds) Lactic Acid Bacteria: Genetics, Metabolism and Applications. Springer, Dordrecht. pp. 217-235.

Kariluoto, S., Vahteristo, L., Salovaara, H., Katina, K., Liukkonen, K.H., Piironen, V. 2004. Effect of baking method and fermentation on folate content of rye and wheat breads. Cereal Chemistry, 81, 134-139.

Li, L., Shewry, P.R., Ward, J.L. 2008. Phenolic acids in wheat varieties in the HEALTHGRAIN diversity screen. Journal of Agricultural and Food Chemistry, 56, 9732-9739.

Nystrom, L., Lampi, A.M., Andersson, A.M., Kamal-Eldin, A., Gebruers, K., Courtin, C.M., Delcour, J., Li, L., Ward, J.L., Fras, A., Boros, D., Rakszegi, M., Bedo., Z., Shewry, P.R., Piironen, V. 2008. Phytochemicals and dietary fiber components in rye varieties in the HEALTHGRAIN diversity screen. Journal of Agricultural and Food Chemistry, 56, 9758-9766.

Poutanen, K., Flande, L., Katina, K. 2009. Sourdough and cereal fermentation in a nutritional perspective. Food Microbiology, 26, 693-699.

Shewry, P.R., Piironen, V., Lampi, A.M., Nyström, L., Li, L., Rakszegi, M., Fras, A., Boros, D., Gebruers, K., Courtin, C.M., Delcour, J.A., Abdersson, A.A.M., Dimberg, L., Bedo, Z., Ward, J.L. 2008. Phytochemical and fiber components in oat varieties in the HEALTHGRAIN diversity screen. Journal of Agricultural and Food Chemistry, 56(21), 9777-9784. 
Singleton, V.L., Rossi, J.A. 1965. Colorimetry of total phenolics with phosphomolybdicephosphotungistic acid reagents. American Journal of Enology and Viticulture, 16, 144-158.

Sybesma, W., Starrenburg, M., Kleerebezem, M., Mierau, I., de Vos, W.M., Hugenholtz, J. 2003. Increased production of folate by metabolic engineering of Lactococcus lactis. Applied and Environmental Microbiology, 69(6), 3069-3076

Tulse, S.B., Reshma, V., Inamdar, A.A., Sakhare, S.D. 2014. Studies on multigrain milling and its effects on physical, chemical and rheology characteristics of milled streams. Journal of Cereal Science, 60, 361-367. 